\title{
La fabricación mediática de la protesta social. Notas acerca de la conformación de una opinión pública despolitizada y estetizante*
}

\author{
Juan Pablo Silva Escobar ${ }^{* *}$ \\ Recibido: 2014-28-10 - Aprobado por pares: 2015-15-01 \\ Enviado a pares: 2014-11-15 - Aceptado: 2015-25-01
}

\begin{abstract}
Resumen
Este ensayo plantea algunas reflexiones teórico-críticas acerca de la despolitización mediática de la protesta social. En este sentido, entendemos que estas representaciones televisivas se inscriben como discursos que conllevan componentes mitificadores y estetizantes que permiten entrever ciertos mecanismos de transferencia ideológica que dan cuenta de la internalización de la hegemonía neoliberal, la cual tiende a reducir y privatizar el discurso político contestatario bajo una forma comprimida y desechable que no puede sino ser un retrato hueco de la deliberación y elucidación de lo político.

Palabras clave: televisión, neoliberalismo, movimiento social, mediaciones, mito.
\end{abstract}

* Este ensayo se desprende de una parte de la tesis doctoral Discurso, representación y cultura. La valoración simbólica de los noticiarios de televisión: los movimientos sociales chilenos y la visibilidad social, presentada por el autor en la Universidad de Valladolid, España, en noviembre del 2013. Investigación doctoral que fue realizada gracias a una beca Erasmus Mundus External Cooperation Window European Commission.

** Dr. en Antropología de Iberoamérica, magíster en Estudios Latinoamericanos, DEA en Antropología Social, Antropólogo. Centro de Estudios Culturales Latinoamericanos (CECLA), Universidad de Chile. E-mail: jp.silva.escobar@gmail.com 


\title{
Mediatic Preparation of Social Protest. Notes about the formation of an opinion full of aesthetics and free from politics
}

\begin{abstract}
This essay poses some theoretical and critical thoughts about the mediatic preparation of social protest free from politics. We understand that these representations on TV inscribe themselves as speeches, which bear mythic and aesthetic components, showing certain mechanisms of ideological transfer, that give an account for the internalization of the neo-liberal hegemony, which tends to reduce and privatize the argumentative political speech under a compressed and disposable form that cannot be but a hollow portrait of the deliberation and elucidation of what is political.
\end{abstract}

Key words: Television, neoliberalism, social movement, mediations, myth 


\section{Introducción}

Pantallas nos informan; pantallas nos ponen en contacto con el mundo; pantallas nos vigilan; pantallas formulan nuestros deseos y extienden nuestros sentidos; pantallas registran, reproducen, producen, crean; pantallas nos sitian; pantallas trazan las señas de nuestra identidad subjetiva y nuestro inconsciente colectivo; pantallas dan cuenta de nuestra felicidad y nuestra desesperación... todo, desde nuestros sueños hasta las grandes decisiones que afectan al porvenir de la humanidad parece haberse convertido en un prodigioso efecto de pantalla.

Eduardo Subirats (2001, p. 7)

El epígrafe que abre nuestro trabajo establece la centralidad que hoy en día, a la luz del capitalismo tardío, juega la pantalla como un dispositivo mediador de los distintos aspectos de la vida social, cultural y política. Como ha observado Jesús González Requena (1999), "la televisión está ahí delante de nosotros. Seguramente nada o casi nada en nuestra experiencia cotidiana ocupa tan insistentemente ese lugar, delante de nosotros, delante de nuestros ojos" (p. 9). De ahí que la televisión se configure mucho menos como un medio visual y mucho más como un objeto visible que, dentro del espacio doméstico, no solo trasmite programas, mensajes y discursos, mitos e ideologías bajo la forma naturalizada de imágenes y sonidos, sino también se configura como una institución socialmente legitimada para elaborar discursos y representaciones que inciden significativamente en la construcción social de la realidad y en la configuración de la opinión pública, articulándose de esta forma como un poder simbólico y una simbólica del poder.

La televisión objetiva, porque crea unas materialidades visuales para aquello que en el imaginario era solo escritura, noción o abstracción. La televisión refleja, porque tiene como punto de partida el material disponible en el imaginario de la época de su realización. La televisión amplifica el imaginario porque lo instala en el dominio colectivo, en las diferentes audiencias a las que está dirigido (Gallardo, 2008). De ahí que, conceptualmente, los noticiarios de televisión serán comprendidos como una práctica significante que no solamente objetiva en la pantalla la imagen visible de las informaciones acerca de los sucesos y acontecimientos del día a día, sino también se instala como parte integral de la cultura de la cual procede, configurándose como elemento constituyente de las relaciones sociales.

El objetivo de nuestro ensayo es analizar la despolitización mediática de la protesta social y reflexionar acerca de cómo esto contribuye en la conformación de una opinión pública despolitizada y estetizante. Se trata, por lo tanto, de analizar cómo las representaciones televisivas de la protesta social se inscriben como dispositivos de significación cultural que conllevan componentes mitificadores y estetizantes, que nos permiten entrever la interiorización social de la hegemonía neoliberal, la cual tiende a reducir y privatizar el discurso político contestatario bajo una forma comprimida y desechable que no puede sino ser un retrato hueco de la deliberación y elucidación de lo político. En este sentido, 
entendemos que los noticiarios de televisión se articulan como un artefacto visual de cultura y poder cuyos contenidos se encuentran determinados por los contextos históricos de su aparición.

\section{De la esfera pública al espacio publicado}

La noción de "esfera pública" ha sido descrita por Habermas (1982) como la instancia moderna fundamental para preservar los sistemas de participación y deliberación política de la sociedad civil. Un tipo ideal que relaciona y vincula el surgimiento de la "opinión pública" con la instalación de un espacio mediador y discutidor - que arranca desde la esfera privada o desde la sociedad civil- que se "enfrenta" al Estado o negocia con él, y que se vuelca sobre asuntos de "interés general". Habermas (1989) propone que la conformación de "lo público" se constituye como un espacio en el que surge la "opinión pública" sobre asuntos diversos en los que confluye el interés de distintas personas. Se trata por lo tanto, de un espacio civil en el cual "la opinión pública, en términos de su misma idea, se forma solamente donde existe un público que se compromete en la discusión racional" (p. 232). De acuerdo con ello, podría pensarse que el desarrollo contemporáneo de este espacio se presenta idealmente potenciado por los medios de comunicación. Sin embargo, lo cierto es que su condición actual está lejos de una concepción ideal.

En términos históricos, el surgimiento de la prensa, hacia finales del siglo XVII, jugó un papel clave en el desarrollo de la esfera pública burguesa ya que ofreció nuevos elementos para el debate público. Es el momento en el cual se produjeron las condiciones sociales y culturales que permitieron el surgimiento de espacios de mediatización de lo social, que estimularon la circulación de una serie de discusiones acerca de un conjunto de problemáticas públicas fuera del ámbito del Estado. En un principio se trató de publicaciones semanales orientadas a la crítica literaria, pero poco a poco fueron interesándose en temas de mayor significación social y política, articulándose como uno de los principales factores que favorecieron la aparición de la moderna opinión pública.

El continuo desarrollo tecnológico experimentado por las industrias de la imagen y las telecomunicaciones no ha hecho más que aumentar la influencia política de los medios de comunicación en la conformación de la opinión pública. Sin embargo, también es detectable un movimiento que va de la prensa como esfera pública a la prensa como espacio de divulgación, en donde lo que está en juego no es el debate sino el aparecer en pantalla. De este modo, se advierte que el escenario televisivo ha hegemonizado el espacio público, constituyéndose en un dispositivo dominante en la producción de la visibilidad social de los actores políticos pero despojados de aquello que justifica su visibilidad. Se articula, entonces, un desplazamiento que va desde la esfera pública al espacio publicado.

\section{Protesta social y medios de comunicación}

Si bien nuestro esfuerzo está destinado a analizar la representación mediática-televisiva que se hace de la protesta social y no la protesta en sí, creemos que es pertinente definir, brevemente, qué entendemos por protesta social, su relación con los medios de comu- 
nicación y cómo ciertas acciones colectivas se adecuan a los criterios del espectáculo televisivo. Partimos de la base de que la protesta social se configura como parte de los repertorios de acción colectiva que tienen los movimientos sociales para lograr visibilidad y reconocimiento social; de ahí que pueda ser comprendida como un dispositivo político estratégico que persigue llamar la atención política y ciudadana. Ante la indiferencia ciudadana, la invisibilidad mediática y la apatía de la autoridades políticas, los movimientos sociales son conscientes de la necesidad de adquirir notoriedad apareciendo en pantalla, para lo que elaboran estrategias de visibilidad y reconocimiento a través de lo que algunos investigadores (Laraña 1999; Tarrow, 2004, Tilly y Wood, 2010; Tilly, 2002), han denominado como ciclos de protestas'

Estos ciclos implican un conjunto de repertorios para la acción colectiva, compuestos por diversas formas verbales, visuales, corporales y escritas, a través de las cuales se articulan las reivindicaciones. Cabría distinguir aquí entre repertorios instrumentales y repertorios de discurso. Los primeros se constituyen bajo la dinámica de lo que se ha denominado marcos de acción colectiva, mientras que los segundos se estructuran como discursos enmarcadores (Traugott, 2002). De este modo, los repertorios de acción colectiva deben entenderse como un conjunto variable de actuaciones y discursos. Se trata, de un uso combinado y entretejido de formas de acción política que van desde la creación de coaliciones, hasta mítines y declaraciones en los medios de comunicación (Tilly y Wood, 2010).

Entre estos repertorios de acción estuvieron las llamadas "otras formas de protestar" realizadas en el marco de la movilización estudiantil chilena del año 2011. "Thriller por la educación chilena"; la "Maratón: 1800 horas por la educación" o la "Besatón por la educación", tenían como finalidad "visibilizar pacíficamente sus demandas por mejoras en el sistema de enseñanza". Estos nuevos repertorios de acción colectica que se articulan en torno al espectáculo y la diversión carnavalesca (en el sentido bajtiano del término) son herederos de la cultura pop y adoptan las transformaciones que se dan dentro de la industria cultural o bien asumen la iconicidad massmediática instalada en el imaginario colectivo. Estas formas de manifestación generaron en la opinión pública y en los medios de comunicación masivos una suerte de "simpatía" de la que no siempre gozaron las marchas tradicionales, producto, en parte, de la cercanía que generó la utilización del lenguaje apolítico del espectáculo que solo adquiere su verdadero significado a través del discurso explicatorio de sus organizadores. En ese sentido, la novedad no está en la acción misma -los smartmob no nacieron como actividades con connotaciones políticas y han sido ampliamente usados por el mundo publicitario- sino en su adopción por los movimientos sociales.

En líneas generales, lo que hay aquí es una profunda conjunción entre protesta y espectáculo televisivo, donde podemos advertir un doble juego que se articula de forma paradójica. Por una parte, estos nuevos repertorios se constituyen en una estrategia discursiva que revela una cierta instrumentalización política de la televisión por parte de los movimientos sociales. Por otra parte, la televisión, a través de la inevitable manipulación 
audiovisual que ejerce sobre los acontecimientos, elabora discursos y representaciones que asumen una visión hegemónica no cuestionada y, a través de la selección y exteriorización de opiniones fundadas principalmente en el sentido común, esconden un marco de interpretación en que la espectacularidad del acontecimiento se rearticula como noticia y entretención. Así, el uso del espectáculo como repertorio para la acción colectiva le permite al movimiento social mantener sus demandas en la agenda, aunque con ello se arriesga a verse sometido a un proceso de domesticación mediática.

\section{Espiral del silencio: entre el cerco informativo y el ocultar mostrando}

Cuando un medio de comunicación establece una determinada agenda, ese acto comunicativo implica una selección y, por lo tanto, la negación de otros acontecimientos. La agenda-setting "asigna un papel central a los medios informativos a la hora de dar inicio al repertorio de la agenda pública" (McCombs, 2006, p. 31), por lo que sería pertinente cuestionar aquello que los medios ocultan o, más bien, deciden deliberadamente no incluir dentro de la composición de su agenda. Se trata de preguntarnos por aquellos acontecimientos sociales que, siendo relevantes para el conjunto de la sociedad, no aparecen en la agenda informativa de los medios. Es lo que se denomina como "cerco informativo", entendido este como la clausura narrativa, el aislamiento discursivo, la incomunicación ideológica y económica de la hegemonía en términos mediáticos (Sel, 2009).

Un ejemplo claro de "cerco informativo" es el que experimentaron 34 presos mapuches quienes, como protesta por ser acusados de infringir la ley antiterrorista, el día 12 de julio de 2010 iniciaron una huelga de hambre indefinida que los mantuvo en ayuno por 82 días. Durante los primeros cincuenta días de huelga, los noticiarios de televisión no informaron absolutamente nada acerca de estos hechos. Uno de los reclamos más frecuentes que realizan dirigentes mapuches, intelectuales y activistas de la causa indígena, respecto a los medios de comunicación masivos y especialmente la televisión, tiene que ver con la exigua cobertura que estos dan a de sus luchas, reivindicaciones o abusos de los que son víctima. Este hecho contrasta con la enorme cobertura en la que se muestran hechos de violencia atribuidos a activistas mapuche, acusaciones de las que posteriormente son absueltos por los tribunales de justicia, lo cual tampoco es informado por los medios de comunicación.

Otra de las caras que adopta la hegemonía discursiva de la televisión respecto de las representaciones de la protesta social, es lo que se ha dado en llamar "ocultar mostrando". El ocultar mostrando puede ser comprendido como una forma más o menos deliberada de despolitizar la protesta social sobre la base de la lógica del informar entreteniendo. Se trata de una figura que "solo consiguen proyectar sobre [la protesta social] sus propias inclinaciones, su propia visión, especialmente cuando el temor a aburrir y, por lo tanto, a que baje el índice de audiencia los lleva a primar la pelea sobre el debate, la polémica sobre la dialéctica, y a hacer cualquier cosa para privilegiar el enfrentamiento entre las personas (los políticos, especialmente) en menoscabo de la confrontación entre sus argumentos" (Bourdieu, 2003, p. 98). Aquí el mundo social, sus demandas y reivindicaciones son 
absorbidos mediáticamente como imagen, representación y espectáculo, apelando a una suerte de sentido común en desmedro de la observación, la explicación y la investigación de los acontecimientos. La retórica asociada al ocultar mostrando se preocupa más por el juego y los jugadores (los políticos y sus conflictos, intereses y desavenencias), y menos por los fundamentos que están en juego (lo político y sus consecuencias sociales, culturales y económicas). Por lo tanto, bajo esta política de la despolitización lo que hay son formas y no contenidos, descripciones y no explicaciones. Ejemplo claro de cómo ha operado el ocultar mostrando en la televisión chilena fue la forma en que los noticiarios elaboraron la cobertura mediática de las protestas estudiantiles iniciadas en abril del 2011.

Ahora bien, la repercusión tanto del "cerco informativo" como del "ocultar mostrando" descansa en un aspecto cultural mayor que tiene relación con lo que Elizabeth NoelleNeumann (1995) ha denominado como espiral del silencio. Este concepto, surgido de la teoría sobre la opinión pública, postula que para evitar el aislamiento en los asuntos públicos importantes, mucha gente se guía por las opiniones que se perciben como dominantes dentro del campo social. Es decir, los sujetos inmersos en determinados contextos históricos, políticos y culturales se dejan influenciar por aquellas opiniones que advierten como socialmente mayoritarias y, por lo general, tienden a disimular sus opiniones cuando estiman que están en minoría (Noelle-Neumann, 1995; McQuail, 2000). En este sentido, tanto "el cerco informativo" en torno a la huelga de hambre mapuche como "el ocultar mostrando" que se impuso mediáticamente sobre las marchas estudiantiles, constituyen una espiral del silencio en la medida en que la televisión contribuyó en la instalación de opiniones y discursos dominantes que se van sedimentando como sentido común y se imponen sobre otras opiniones y discursos. Este tipo de estrategias discursivas realzan el hecho de que la televisión no impone una ideología dominante, sino que contribuye a que esta se naturalice en virtud de un consenso no cuestionado.

\section{La fabricación mediática de la protesta social}

Una de las primeras características que se destacan al analizar la fabricación mediática de la protesta social, es la parcialidad con la que se representan ciertos acontecimientos: existen ciertas luchas, reivindicaciones y malestares sociales que reciben un tratamiento benévolo y otros que se muestran de forma más implacable. Esta discriminación tiene que ver con el grado de incomodidad ideológica que genera cada una de las luchas sociales. Por lo general, el tratamiento es más despiadado con aquellos movimientos que poseen un componente político, como es el caso de las luchas estudiantiles, indígenas y sindicales. Estas luchas, principalmente las sindicales y estudiantiles, se inscriben dentro de una larga historia de movilización social en Chile y llevan residualmente inscrita en sus demandas la lucha de clases y la transformación política; de allí que el noticiario, que busca entregar una mirada despolitizada de la sociedad, opte por la desacreditación del movimiento a través de la criminalización. Se condenan el caos y el desorden con el que se asocian las manifestaciones callejeras de este tipo de luchas porque se percibe que estas son parte constitutiva de las demandas que las motivan y que buscan distorsionar el orden establecido. En oposición a las luchas más políticas, los movimientos vinculados a la lucha 
por el reconocimiento social, como son las luchas ecológicas o las reivindicaciones de las minorías sexuales reciben un tratamiento informativo más lúdico y benévolo, porque son vistas como reivindicaciones apolíticas y transversales socialmente.

La división entre informaciones que son "dañinas" para el sistema neoliberal y aquellas que le son menos problemáticas implica que el noticiario asuma estrategias narrativas y discursivas diferenciadas de acuerdo con el énfasis que le quiera imprimir al relato. Sin embargo, más allá de esta particular forma de clasificar las protestas sociales, existen algunas características comunes en el modo en que se construye la noticia en general y las protestas sociales en particular, lo cual se puede relacionar con la idea de que el tiempo mediático es un tiempo comprimido que se moviliza bajo la lógica de lo inmediato.

La inmediatez y trivialidad con que se elaboran, se hacen circular y se desechan las informaciones referidas a la protesta social no dejan tiempo ni a la reflexión, ni a una mirada más analítica, dialéctica o crítica. Por ello, los malestares sociales mediatizados por la televisión emergen solo como enunciaciones primarias en las que es posible detectar ciertas cualidades como son el flujo constante, la descontextualización de los acontecimientos sociales, la inclinación hacia los eventos espectaculares y la fascinación por el despacho en directo en tiempo real. Esta forma de construir las informaciones deja entrever un cierto contrasentido: "cómo una producción tan racional puede resultar en la increíble irracionalidad de las sobrecargas de información, la información errónea, la desinformación y la información descontrolada. Se juega aquí una sociedad desinformada de la información" (Lash, 2005, p. 23).

Una de las formas que adopta la desinformación es la excesiva individualización que se hace de los movimientos sociales. En las pantallas de nuestros televisores, unos pocos dirigentes parecieran encarnar el movimiento social en su conjunto, obviando de esta forma el carácter masivo y diverso que han alcanzado las movilizaciones sociales en Chile en el último tiempo. Se promueve así la idea de que los dirigentes son el movimiento social y no solo una parte significativa de estos. La individualización se configura como un mecanismo de reducción que permite la gobernabilidad de la información, comprimiendo los acontecimientos sociales ligados a la protesta social y despojándolos de su densidad y de su historicidad. De modo que el noticiario televisivo se articula como un territorio informacional en el que, "tras haber vaciado los acontecimientos de su sustancia, se recrea una gravedad artificial y se los vuelve a poner en órbita en tiempo real, en el que, después de haberlos desvitalizado históricamente, se los proyecta de nuevo en el escenario transpolítico de la información" (Baudrillard, 2000, p. 136). Esta desustancialización de las informaciones referidas a los movimientos sociales es la materialización y "la emergencia de una razón comunicacional cuyos dispositivos -la fragmentación que disloca y descentra, el flujo que globaliza y comprime, la conexión que desmaterializa e híbrida- agencian el devenir mercado de la sociedad" (Martín-Barbero, 2002, p. 15).

Este devenir mercado implica centrar las informaciones no solo bajo la lógica de la individualización, sino someterlas a un tratamiento que permita al noticiario mantenerse 
flexible, acomodándose a las circunstancias, cambiando su punto de vista de un momento a otro sin que ello se perciba como una contradicción. Esto le permite, por ejemplo, en un momento determinado construir una visión criminalizadora del movimiento social y, en la siguiente nota exaltar la creatividad y el ingenio de las movilizaciones sociales. Esto es posible gracias a la descontextualización de los acontecimientos y su integración bajo un relato que apela a la objetividad en el sentido de factualidad.

La selección y los puntos de vista asumidos y puestos en circulación por el noticiario deben entenderse como ideológicos, porque estos se encuentran integrados dentro de una lógica de racionalización que hace que "veamos el mundo como algo que en cierto modo está naturalmente orientado hacia nosotros, espontáneamente 'dado' al sujeto; y el sujeto, a la inversa, se siente a sí mismo como parte natural de esa realidad demandada y requerida por él" (Eagleton, 2003, p. 240). En este sentido, la televisión en general y los noticiarios en particular tienen la capacidad de separar y unificar, "de realizar incesantemente el trabajo ideológico crítico de clasificar el mundo dentro de los discursos de las ideologías dominantes" (Hall, 1981, p. 390).

De este modo, la protesta social es vuelta inteligible dentro los códigos del sistema simbólico del noticiario televisivo, y es en esa representación cuando el punto de vista favorable al orden capitalista neoliberal se codifica en los mensajes de tal modo que sugiere una interpretación o "lectura preferente" a la que cuesta resistirse. Para dar cuenta de ello, haré referencia a los tres tipos de discursos a los que el noticiario de televisión echó mano para fabricar una visión mediática de la huelga de hambre mapuche bajo el paraguas de la ideología neoliberal.

Se trata de los discursos criminalizante, victimizante y paternalista. El primero, el discurso criminalizante, es un discurso que se construye a partir de una mirada alarmista y hasta cierto punto censuradora del movimiento mapuche, en la medida en que las demandas surgidas desde el movimiento son presentadas como una amenaza a la estabilidad de la razón neoliberal. Bajo este tipo de discurso son inscritas mayoritariamente aquellas reivindicaciones que se encuentran signadas por la lucha de clases, especialmente las movilizaciones referidas a las tomas de terreno. El discurso victimizador, en cambio, construye una representación de los actores sociales como vulnerados por circunstancias injustas. Bajo esta perspectiva se abordan las luchas indígena-ecológicas que buscan defender la naturaleza como un bien comunitario. Por último, el discurso paternalista recurre a una aparente neutralidad y objetividad para enfatizar la necesidad de poner fin a un conflicto, pero en última instancia se centra en la inmediatez del problema puntual, omitiendo las cuestiones de fondo. Esta última fue la más utilizada en el caso de la huelga de hambre, en el que la información se centró en las mediaciones y procedimientos para salvar las vidas de los huelguistas. Me parece necesario señalar que estos tres tipos de discursos no se presentan de forma pura, sino como una hibridación en la que predomina uno u otro, produciendo así una tendencia que nos permite clasificar operativamente una determinada representación. 
Las representaciones televisivas del malestar social conllevan una mediación en la que se dejan entrever tres grandes mecanismos de transferencia ideológica: "el primer efecto general ideológico bajo el capitalismo tardío parece ser el de enmascarar y desplazar" (Hall, 1981, p. 380). Esto queda reflejado en las informaciones referidas a los movimientos sociales, cuando advertimos que los malestares sociales son constantemente ocultados y desplazados de su postura contra-hegemónica. El segundo efecto ideológico es el de la fragmentación que, a través de la descontextualización de las informaciones referidas a la protesta social y de la iconización del movimiento social en un reducido grupo de dirigentes, persigue negar los intereses de las clases trabajadoras como colectivo, fragmentándolos "en oposiciones internas entre los diferentes estratos de la clase. El valor colectivamente creado es apropiado individual y privadamente" (Hall, 1981, p. 380). Y, finalmente, el tercer efecto general ideológico sería "el de imponer una coherencia o unidad imaginaria sobre las unidades así representadas (Hall, 1981, p. 381). Se trata aquí de imponer un sentido común que, bajo el dominio de la doxa, persigue reunir a todas las clases sociales y a las personas bienintencionadas bajo el dominio neoliberal y realizar así, "el sueño de todas las burguesías: existir sin un proletariado" (Bourdieu, 2002, p. 64).

\section{Hegemonía y mitificación}

La televisión, como nos recuerda Pierre Bourdieu, fue concebida ideológicamente como una herramienta tecnológica que procuraba ser una suerte de ventana abierta al mundo y pretendía "ser un instrumento que refleja la realidad, acaba convirtiéndose en instrumento que crea una realidad" (1997: 28). Como lo han demostrado varias investigaciones (Gitlin, 1980; Gamson y Modigliani, 1989; Van Zoonen, 1992), la televisión elabora una cobertura mediática sobre los movimientos sociales, que no solo pone en pantalla la visión dominante de las élites políticas o económicas, sino que también desempeña un rol central en la configuración de la imagen y opinión que del movimiento social se hacen las audiencias. Esta imagen es construida, en parte, de acuerdo con las propias necesidades del medio televisivo, como por ejemplo, la creación de secuencias espectaculares que incluyan acción, frases altisonantes de personalidades y conflictos bien definidos entre el bien y el mal; y en muchos casos los mismos movimientos sociales adaptan sus repertorios de acción para acomodarse a las convenciones del relato audiovisual y de la televisión como entretenimiento.

La eficacia simbólica e ideológica que posee la televisión reside, en gran medida, en su enorme capacidad para exponer, dramatizar, popularizar y "formar tendencias ideológicas que representan excesivamente los intereses de los poderosos y subrepresentan los intereses de los demás" (Lull, 1997, p. 22).

Estas capacidades se fundan, siguiendo a Roland Barthes (1999), en que las notas televisivas, en tanto discursividades que poseen un componente mitificador del mundo social, tienden a transformar en naturaleza, "lo que es intención histórica; como eternidad, lo que es contingencia. Este mecanismo es, justamente, la forma de acción específica de la ideología" (p. 198). De este modo, el noticiario tiene la potencia de transfigurar o defeccionar los acontecimientos sociales, que siempre están envueltos y compuestos por 
una historicidad y una cualidad sociocultural, en discursos naturalizados y mitificados que pierden su densidad sociohistórica y su historicidad cultural. Se transforman, así, en pura contingencia que extravía o distrae la espesura de su genealogía, articulándose como "una prestidigitación que trastoca lo real, lo vacía de historia y lo llena de naturaleza" (Barthes, 1999, p. 199).

En consecuencia, cuando el noticiario elabora representaciones, informaciones y discursos acerca de los movimientos sociales, se configura como un habla mítica despolitizada. El mito que se construye noticiosamente acerca de los movimientos sociales no niega los hechos -los muestra, y habla de ellos-, pero los significa desprovistos de su historicidad cultural, es decir, los filtra, los vuelve inocentes, higiénicos y los reviste como naturaleza. Se trata de un mito que despolitiza la lucha por el reconocimiento, las demandas sociales y sus reivindicaciones, a través de la puesta en pantalla de informaciones que confieren una claridad discursiva que no se concentra en proporcionar una explicación sino entregar una comprobación.

El noticiario se concentra en desarrollar una labor demostrativa y comprobativa que signa los hechos referidos a los movimientos sociales como violentos, provocadores de destrozos a la propiedad pública y privada, perturbadores del orden de las cosas y alteradores del devenir ciudadano-cotidiano. Carentes de cualquier contextualización o explicación, es muy fácil que ese tipo de "comprobaciones" se naturalicen y, mediante esa naturalización mítica, se despolitice el contenido profundo, político e histórico inscrito en las demandas "reales" de los movimientos sociales. De este modo, como ha observado Roland Barthes (1999),

Al pasar de la historia a la naturaleza, el mito efectúa una economía: consigue abolir la complejidad de los actos humanos, les otorga la simplicidad de las esencias, suprime la dialéctica, organiza un mundo sin contradicciones puesto que no tiene profundidad, construye un mundo desplegado en la evidencia y funda una claridad feliz: las cosas parecen significar por sí mismas (pp. 199-200).

Esto trae como resultado la circulación de representaciones que, ideológicamente, tienden a la tachadura o borramiento del acontecimiento político inscrito en la movilización y lo instala dentro de una cadena de significación en la que prima una representación que acomoda los hechos y los acontecimientos bajo un orden discursivo que le inflige una operación de ex-nominación. Es decir, se define, se construye y se hace circular mediáticamente una imagen de la protesta social que no quiere ser nombrada como tal, que no quiere ser signada bajo la problemática de lo político, y su despolitización se inicia con el conjunto de dispositivos retóricos y visuales propios de la televisión (duración de las notas, cuñas, montaje, voz en off, etc.), por medio de los cuales el conflicto social político deviene en criminal, terrorista o, en el mejor de los casos, en una fiesta multicolor de baile y espectáculo. Estas cotidianidades pierden el poder de interpelarnos: "ya no se trata de lo que se vive, sino de lo que puede verse o de lo que se exhibe, del espectáculo y de la descripción, sin que entre ello exista ninguna relación activa. Se nos ofrece el mundo entero, pero solo con la mirada" (Blanchot citado en Jay, 2007, p. 326). 
La despolitización final, como sugiere Sergio Rojas (2012), consistiría en el agotamiento de las representaciones que habrían servido tanto a la normalización del conflicto, como a su extrema visibilidad en los momentos de agitación. En consecuencia, la despolitización significa hoy una cierta invisibilidad del conflicto social. La construcción mediática de la sociedad despolitizada no consiste sino en la idea de que la esfera pública, como espacio de deliberación y elucidación de la comunidad de individuos, es algo que no tiene mayor trascendencia y, en esa situación límite, emerge el mito neoliberal que hace de las prácticas culturales un asunto de "la naturaleza humana".

Si el noticiario construye un mito despolitizado acerca de los movimientos sociales, este mito opera como un metalenguaje que, a partir de la legitimidad social alcanzada por el noticiario de televisión, pretende entregar transparencia y objetividad naturalizando el discurso periodístico. Sin embargo, en ese proceso mítico, el noticiario se vuelve opaco en la medida en que excluye, reemplaza y hace circular verdades que se presentan como ortodoxas y se van transformando en cánones que no admiten ni discusión ni disputa. Como tales son incorporadas e internalizadas dentro del campo social, sin haber pasado por el cedazo ni de la deliberación y mucho menos de la elucidación de las motivaciones y prioridades del medio periodístico.

En última instancia, la respuesta del medio televisivo a las movilizaciones es un discurso que insiste en la necesidad urgente de restablecer el orden de las cosas, de volver a la cotidianidad y a la normalidad neoliberal. El resultado es la circulación de un escenario político-social mediatizado que evidencia que una de las grandes problemáticas de nuestra contemporaneidad es que ha dejado de ponerse a sí misma en tela de juicio, de pensarse y explicarse, para transformarse casi exclusivamente en representación, imagen, mercado, consumo, espectáculo y mito.

\section{Conclusiones}

Las representaciones que hace circular la televisión sobre el malestar social son construcciones que, por un lado, fabrican discursos y representaciones que nos conducen a la desaparición mediática del movimiento social, porque este es deprendido de sus reivindicaciones políticas en los medios televisivos, ya sea mediante una sobreexposición mediática que apela al espectáculo del "ocultar mostrando" o ya sea a través de una subexposición que apela a la censura del "cerco informativo".

Por el otro lado, advertimos que la construcción mediática de la protesta social, al ser construida baja la tachadura y el borramiento de un mito como habla despolitizada, es enfrentada desde el movimiento social como una lucha por la visibilidad y el reconocimiento. Esto nos habla, en última instancia, de una lucha por el derecho a la imagen y, como nos recuerda Didi-Huberman (2014), la imagen mantiene una relación antropológica de muy larga data con las cuestiones relativas al derecho civil, el espacio público y la representación política. Sin embargo, en la actualidad, "ese derecho - nos dice Didi-Huberman-se ha convertido, hoy más que nunca, en una cuestión de propiedad privada: lo contrario, por lo tanto, de una dignidad republicana que ningún sujeto, en teoría, tiene derecho a atribuirse y menos aún a comprar". (2014, p. 15). 
En definitiva, este borramiento mediático que se hizo de la protesta social responde, estética y políticamente, a una cuestión de asimetría entre palabra e imagen, entre representación y representados, entre inscripción y desciframiento, confeccionando una discursividad respecto de la huelga de hambre que se inscribe, siguiendo a Lucien Sfez (1995), dentro de la lógica del "tautismo"; es decir, se construyen representaciones audiovisuales que circulan bajo el signo de unos discursos iterativos que replican incesantemente un mismo mensaje y, al mismo tiempo, son representaciones pasivas, sordas y autorreferenciales que se han enclaustrado bajo una lógica circular, totalizante y totalitaria, que busca hacernos creer, y de ahí su potencia ideológica, que estamos ante la expresión inmediata y directa, allí donde en realidad se construye una representación, es decir, una ficción que comporta una comunicación circular, cuyo sujeto, verbo y predicado son un solo y mismo concepto.

\section{Notas}

1 Como ha observado Enrique Laraña (1999: 245), "la primera acepción de esta expresión se plantea en la botánica, y está relacionada con la concepción organicista y clásica del cambio social y de los movimientos que lo producen, la cual sitúa sus causas en el interior del objeto en transformación. Es la concepción que ha prevalecido en nuestra cultura, basada en una analogía entre el cambio social y el biológico y en una metáfora procedente de la observación de los fenómenos naturales. Desde la Antigüedad clásica, la semilla es el símbolo del crecimiento, el principio generativo de los ciclos de nacimiento, apogeo y decadencia de las plantas (...) Un ciclo es un periodo de tiempo 'que se considera completo desde cierto punto de vista', por ejemplo: 'La invasión de los bárbaros cierra un ciclo de la historia' (...). En congruencia con esa analogía entre lo que sucede en el mundo biológico y en el social, un ciclo está integrado por una serie de acciones, acontecimientos o fenómenos que se suceden hasta uno desde el cual vuelven a repetirse en el mismo orden, y es un espacio de tiempo o serie de años, transcurridos los cuales se recomienza el cómputo".

\section{Bibliografía}

Barthes, R. (1999). Mitologías. México DF: Siglo XXI Editores.

Baudrillard, J. (2000). El intercambio imposible. Madrid: Cátedra.

Bourdieu P. (2003). "La televisión, el periodismo y la política" En Pierre Bourdieu Contrafuegos. Reflexiones para servir a la resistencia contra la invasión neoliberal. Barcelona: Anagrama, pp. 95-106.

Bourdieu P. (2002). Pensamiento y acción. Buenos Aires: Libros del Zorzal.

Bourdieu P. (1997). Sobre la televisión. Barcelona: Anagrama.

Didi-Huberman, G. (2014). Pueblos expuestos, pueblos figurantes. Buenos Aires: Manantial.

Eagleton, T. (2003). "La ideología y sus vicisitudes en el marxismo occidental" En Slavoj Zizek (comp.) Ideología. Un mapa de la cuestión. Buenos Aires: Fondo de Cultura Económica, pp. 199-251.

Gallardo, F. (2008). "Elementos para una antropología del cine: los nativos en el cine de ficción de Chile". En Chungará, Revista de Antropología Chilena, Vol. 40, número especial, pp. 79-87.

Gamson, W. Y A. Modigliani. (1989). "Media Discourse and Public Opinion on Nuclear Power: A Constructionist Approach" In American Journal of Sociology Vol. 95, The University of Chicago Press, pp. 1-37.

González Requena, J. (1999). El discurso televisivo. Espectáculo de la posmodernidad. Madrid: Cátedra. 
Gitlin, T. (1987). The whole Word is watching. Mass media in the making \& unmking of the new left. California: University of California press, Berkeley.

Gusfield, J. (2001). "La reflexividad de los movimientos sociales: revisión de las teorías sobre la sociedad de masas y el comportamiento colectivo". En Enrique Laraña y Joseph Gusfield (Ed.) Los nuevos movimientos sociales. De la ideología a la identidad. Madrid: Centro de Investigaciones Sociológicas (CIS), pp. 93-117.

Habermas, J. (1982). Historia y crítica de la opinión pública. La transformación estructural de la vida pública. Barcelona: Gustavo Gili.

Habermas, J. (1989). "The Public Sphere". In Steven Seidman (ed.), Jürgen Habermas on Society and Politics. A reader. Boston: Beacon Press, pp. 231 - 236.

Hall, S. (1981). "La cultura, los medios de comunicación y el efecto ideológico". En Curran, James, Michael Gurevitch, Janet Woollacott (Comp.) Sociedad y comunicación de masas. México DF: Fondo de Cultura Económica, pp. 357-392.

Jay, M. (2007). Ojos abatidos. La denigración de la visión en el pensamiento francés del siglo XX. Madrid: Akal. Laraña, E. (1999). La construcción de los movimientos sociales. Madrid: Alianza.

Lash, S. (2005). Crítica de la información. Buenos Aires: Amorrortu Editores.

Lull, J. (1997). Medios, comunicación, cultura. Aproximación global. Buenos Aires: Amorrortu Ediciones.

Martín-Barbero, J. (2002). "Pistas para entre-ver medios y mediaciones". En Signo y Pensamiento 41 volumen XXI julio-diciembre, Universidad Javeriana, Colombia, pp. 13-20.

McCombs, M. (2006). Estableciendo la agenda. El impacto de los medios en la opinión pública y en el conocimiento. Barcelona: Paidós.

McQuail, D. (2000). Introducción a la teoría de la comunicación de masas. Barcelona: Paidós.

Neveu, E. (2006). Sociología de los movimientos sociales. Barcelona: Editorial Hacer.

Noelle-Neumann, E. (1995). La espiral del silencio: opinión pública, nuestra piel social. Barcelona: Paidós.

Rojas, S. (2012). "La experiencia agotada". Ponencia presentada en el Coloquio Internacional Transdisciplinar en Artes y psicoanálisis Malestar y destinos del Malestar, Universidad de Chile, 25 al 27 de octubre, en Santiago de Chile.

Sel, S. (2009). "Comunicación alternativa y políticas públicas en el combate latinoamericano". En Sel Susana (comp.) La comunicación mediatizada: hegemonías, alternatividades, soberanías. Buenos Aires: CLACSO, pp. 13-36.

Sfez, L. (1995). Crítica de la comunicación. Buenos Aires: Amorrortu Ediciones.

Subirats, E. (2001). Culturas virtuales. Madrid: Editorial Biblioteca Nueva.

Tarrow, S. (2004). El poder en movimiento. Los movimientos sociales, la acción colectiva y la política. Madrid: Alianza.

Tilly, Ch. (2002). "Repertorios de acción contestataria en Gran Bretaña, 1758-1834". En Traugott Mark (Comp.) Protesta social. Repertorios y ciclos de la acción colectiva. Barcelona: Editorial Hacer, pp. 17-48.

Tilly, Ch. Y L. Wood. (2010). Los movimientos sociales, 1768-2008. Desde sus orígenes hasta Facebook. Barcelona: Editorial Crítica.

Traugott, M. (2002). "Introducción Pautas recurrentes de acción colectiva" En Traugott Mark (Comp.) Protesta social. Repertorios y ciclos de la acción colectiva. Barcelona: Editorial Hacer, pp. 1-16.

Van Zoonen, E. (1992). "The women's movemente and the media construcing a public identity". En European Journal of Communication N. ${ }^{\circ}$ 7, pp. 453-476. 